Brit. F. vener. Dis. (1973) 49, 413

\title{
Long-term results of penicillin treatment of early and late forms of syphilis in the rabbit
}

\author{
N. M. OVČINNIKOV, S. E. KORBUT, V. N. BEDNOVA, G. F. TIMČENKO, AND \\ T. I. MILONOVA \\ From the Microbiology Department, Central Institute for Research on Skin and Venereal Diseases, Moscow, U.S.S.R
}

Penicillin is an excellent remedy for syphilis. The speed with which the treponemes disappear from primary lesions and the way in which clinical manifestations resolve and serological tests become negative in many patients have raised hopes of a complete and rapid cure for syphilis, and in some quarters have even inspired hopes of complete eradication of the disease. The results of treatment were so good that a number of authors started to treat syphilis with a single administration of a penicillin preparation such as PAM and believed that they had cured their patients. The fact that a considerable number of relapses were observed among such patients was attributed to re-infection.

Soviet venereologists give several courses of treatment to patients with syphilis, the number of courses varying with the stage of the disease.

It has been established by many workers that different quantities of penicillin are required for the treatment of early and late forms of syphilis, but in the case of late forms, even when the treatment is carried out thoroughly, serological reactions often remain positive. In cases in which a large quantity of penicillin has been administered and in which there are no clinical manifestations, many workers have recommended that importance should not be attached to positive results from the immobilization test and the classical standard serological tests and have considered the patients to be cured, regarding the positive results as a 'serological scar'.

Some workers, on the other hand, believe that positive TPI results are an indication of the presence of treponemes in the patient's body. But no conclusive experimental research was done by either group until that of Collart, Borel, and Durel (1962a, b, c) and Collart, Dunoyer, and Dunoyer $(1964,1967)$.

Collart and his colleagues set out the material supporting their views. Their main propositions are as follows:

Received for publication October 16, 1972

Address: Prof. N. M. Ovčinnikov, as above.
(1) Treatment that is started late, however good it may be, is unable to destroy all the treponemes which in the course of the disease have penetrated deep into the tissues.

(2) The presence of immobilizing antibodies is evidence of contact between the patient and the treponeme, and investigations would seem to show that positive TPI results, when syphilis is treated late, indicate the presence of treponemes in the tissues.

(3) When the disease has been in the latent stage for a long period, the micro-organisms have lost all or part of their virulence and they vegetate in the tissues in a state of symbiosis.

(4) Under the influence of biological conditions unknown to us, these treponemes may regain all or part of their virulence and become pathogenic, at any rate in regard to their host.

When treatment is started late, a curious state of equilibrium has been created between the host, mobilizing his defences, and the parasite occurring in the tissues. This latent condition, like 'clinical cure', by no means indicates bacteriological sterilization. Collart's main conclusions are based on a large number of experiments on animals and observations on humans.

The experimental research of Collart and his colleagues has been confirmed in varying degrees by Yobs, Rockwell, and Clark (1964), Goldman and Girard (1967), Smith and Israel (1967, 1968), and other writers. Willcox (1964) cast doubt on the significance of Collart's results, pointing out that the structures seen were perhaps not Treponema pallidum, and he set aside the positive results they obtained by infecting rabbits with lymph nodes of treated infected subjects. Guthe and Idsøe (1967) said that Collart's research should be considered in the light of the latest data on treponematoses, mentioning the work of Fribourg-Blanc (1966), who observed, in the lymph nodes of African monkeys with positive TPI and fluorescent antibody test results, dormant treponemes which became pathogenic after passage 
to hamsters, and also the research of Smith and Israel (1967, 1968), who found treponemes in the aqueous humour of the eye of subjects with late forms of syphilis.

The present authors believe that this research by Collart and his colleagues is of immense importance and that if their findings are confirmed the reasons for them should be enquired into and more effective methods of treatment sought. We accordingly began, in 1964, to check Collart's works. The results of treating rabbits having early forms of syphilis with penicillin of different types and varying dosages have been published in a large number of papers by Ovčinnikov (1955a, b), Ovčinnikov, Kucinska, and Zelikova (1953), Ovčinnikov, Kutukova, and Korbut (1957), and Ovčinnikov and Korbut (1959, 1960, 1965). It was established that a total dose of 168,000 units of penicillin is effective. Only in two out of 58 rabbits treated by Ovčinnikov and others (1953) with 168,000 units penicillin per kg. of the rabbit's weight in divided doses every 2 hours for 7 days, were serological relapses observed after 3 months and, in those, the serological reactions became negative again 2 weeks later. 6 to 7 months after the end of treatment a first passage of lymph nodes was made from 29 of the treated rabbits to 85 fresh rabbits, and 6 months later a second passage was made from 49 rabbits to 106 rabbits. Neither in the first-passage nor in the second-passage rabbits were there any clinical manifestations. Re-infection with the same strain gave positive results. These experiments involving long-term observations on large numbers of treated rabbits demonstrated the effectiveness of treatment with 168,000 units penicillin per kg. given as described. Total doses of 42,000 and 84,000 units were too small: serological relapses were observed and, in the case of 42,000 unit, clinical relapses also. Transfer of lymph nodes to healthy rabbits sometimes gave positive results.

The paper of Ovčinnikov and Korbut (1959) reported the long-term results of treating rabbits with primary syphilis with 84,000 and 168,000 units of bicillin $I^{\star}$ and III $†$ per kg. In 26 rabbits treated with 84,000 units of bicillin I (Table I), no clinical or serological relapses occurred. In a first passage from seventeen rabbits to 34 , a chancre formed in one rabbit. In a second passage (from 24 rabbits to 48 ) there were no clinical manifestations in any of the rabbits. Re-infection of treated rabbits (17) was positive in twelve, and in one rabbit positive results were obtained in standard serological tests. Reinfection of eighteen first-passage rabbits produced chancres in thirteen, positive standard test results in one, and negative results in four. In 28 secondpassage rabbits, chancres formed in 24 , and did not develop in four.

Treatment with the same dosage of bicillin III, administered to forty rabbits, had less good results: in a first passage, from 26 treated rabbits to 31 healthy ones, three chancres formed. Upon reinfection of sixteen treated rabbits chancres formed in fourteen and serological reactions became positive in one. Re-infection of eighteen first-passage rabbits produced chancres in twelve, while standard serological reactions became positive in one, and out of 29

*Benzathine penicillin

†A mixture of benzyl penicillin, procaine penicillin, and benzathine penicillin

TABLE I Long-term results of treatment of syphilis with 84,000 u./kg. bicillin I related to when treatment began

\begin{tabular}{|c|c|c|c|c|c|c|c|c|c|}
\hline \multirow[b]{2}{*}{ Diagnosis } & \multirow[b]{2}{*}{$\begin{array}{l}\text { Duration of } \\
\text { disease }\end{array}$} & \multirow[b]{2}{*}{$\begin{array}{l}\text { Number of } \\
\text { rabbits }\end{array}$} & \multicolumn{2}{|c|}{ First transfer } & \multicolumn{2}{|c|}{ Second transfer } & \multicolumn{3}{|c|}{ Re-inoculation $\mathrm{cd}^{\mathrm{d}}$} \\
\hline & & & Number & Result & Number & Result & $\begin{array}{l}\text { Initial } \\
\text { rabbits }\end{array}$ & $\begin{array}{l}\text { First-passage } \\
\text { rabbits }\end{array}$ & $\begin{array}{l}\text { Second-passage } \\
\text { rabbits }\end{array}$ \\
\hline Chancres & & & $34^{b}$ & & $48^{b}$ & & $\begin{array}{l}\text { Ch } 12+ \\
\text { S } 1+ \\
70 \text { per cent. }\end{array}$ & $\begin{array}{l}\text { Ch } 13+ \\
\text { S } 1+ \\
70 \text { per cent. }\end{array}$ & $\begin{array}{l}\text { Ch } 24+ \\
85 \text { per cent. }\end{array}$ \\
\hline & & & $24^{b}$ & S $2+$ & $26^{b}$ & & $\begin{array}{l}\text { Ch } 0+ \\
0 \text { per cent. }\end{array}$ & $\begin{array}{l}\text { Ch } 3+ \\
\text { S } 3+ \\
23 \text { per cent. }\end{array}$ & $\begin{array}{l}\text { Ch } 8+ \\
\text { S } 3+ \\
57 \text { per cent. }\end{array}$ \\
\hline & 2 yrs & 18 & $13^{\mathrm{a}}$ & Ch $2+$ & $10^{3}$ & $\operatorname{Ch} 2+$ & 12 & 12 & 8 \\
\hline & & & $13^{b}$ & s $5+$ & $10^{b}$ & S $2+$ & $\begin{array}{l}\text { Ch } 0+ \\
\text { S } 4+ \\
0 \text { per cent. }\end{array}$ & $\begin{array}{l}\text { Ch } 2+ \\
\text { S } 4+ \\
16 \text { per cent. }\end{array}$ & $\begin{array}{l}\text { Ch } 2+ \\
S 11+ \\
25 \text { per cent. }\end{array}$ \\
\hline
\end{tabular}

Numerator: number of rabbits from which transfers made bDenominator: number of rabbits to which transfers made

- Numerator: total number of rabbits

Denominator: number of rabbits infected
$\mathrm{Ch}=$ chancre

$\mathrm{S}=$ standard serological tests

dPercentages refer to those which developed chancres 
TABLE II Long-term results of treatment of syphilis with 168,000 u./kg. bicillin I

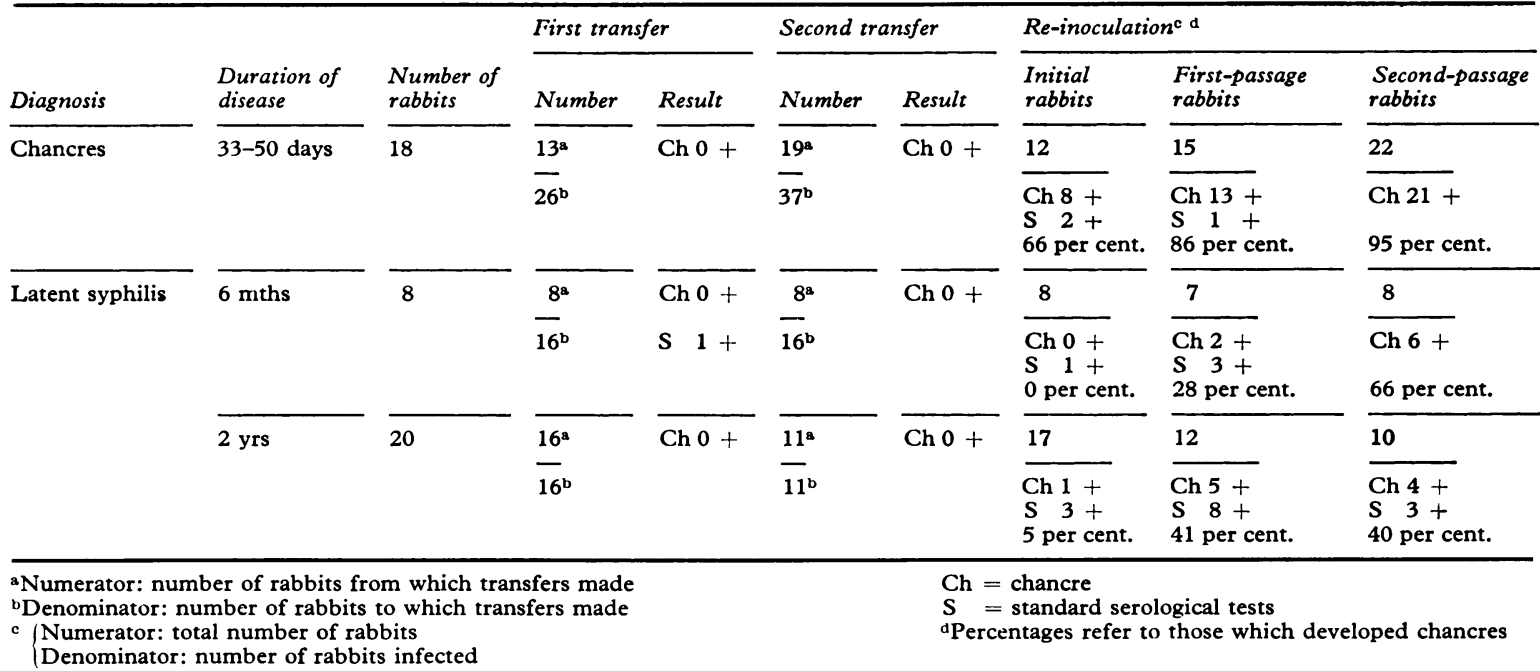

second-passage rabbits chancres formed in 25 and standard reactions became positive in one.

Still better long-term treatment results were obtained by treating rabbits with 168,000 units of bicillin I per kg. (Table II). The results of standard serological tests became negative in all the rabbits.

Ovčinnikov and Korbut (1959) also treated with bicillin I rabbits which had latent syphilis acquired 6 to $7 \frac{1}{2}$ months previously. Results of the Wassermann and precipitation tests before treatment were positive in three and four cases respectively. After twelve rabbits had been treated with 84,000 units of bicillin I per kg. results of the serological tests remained unchanged and there were no clinical manifestations. When treated rabbits were reinfected, no chancres formed. Of 24 first-passage rabbits inoculated with lymph nodes from the treated rabbits $4 \frac{1}{2}$ to 6 months after treatment ended, none developed chancres. On their being re-infected with the same strain, chancres developed in three out of thirteen, and in three the results of the serological tests became positive. After a second passage to 26 rabbits, serological reactions remained negative and there were no clinical manifestations. On fourteen of these being re-infected, chancres developed in eight and in three serological reactions became weakly positive.

After eight rabbits had been treated with 168,000 units of bicillin I per kg., approximately the same results were obtained: there were no clinical or serological changes. After re-infection of the treated rabbits with the same strain, chancres did not develop. No chancres formed in the first passage (16 rabbits) or in the second (16 rabbits). In one firstpassage rabbit there were positive serological results with a titre of 1 in 40 .

On re-infection of first-passage rabbits, two chancres were obtained, and on re-infection of second-passage rabbits six chancres.

Thus the results of treating with bicillin I rabbits in which the age of infection was from 33 days to $7 \frac{1}{2}$ months were relatively satisfactory. Only the reinfection experiments, involving both treated and passage rabbits raised doubts whether a substantial number of the rabbits had been cured. At that time we were not making a regular examination of the rabbits' lymph nodes for treponemes or performing the TPI and fluorescent antibody tests.

\section{Present investigation}

When the papers of Collart and his colleagues appeared, we decided to test the effectiveness of penicillin treatment in rabbits in which the duration of the disease since infection was 2 to 3 years. The experiment on each rabbit lasted from 4 to $4 \frac{1}{2}$ years, and the lymph nodes were also examined for treponemes.

The total number of rabbits in the experiment was $245 ; 74$ were infected and treated and to the remaining 171 transfers of lymph nodes were made in two passages.

Before the rabbits were treated, the blood serum of all of them was tested (TPI and FTA-10 (unabsorbed), Wassermann, Kahn, and citochol tests) and the lymph nodes were examined for the presence of treponemes (darkfield microscopy, preparation 
impregnated with silver by the Morozov and Dunoyer methods, staining by the RomanovskyGiemsa method, and direct and indirect but unabsorbed fluorescent antibody methods). A second half of the lymph node was transferred to healthy rabbits in a skin pouch on the scrotum. In evaluating the treponemes found, the authors recorded as positive only those which were morphologically typical; otherwise they were recorded as 'treponeme-like structures'.

Table III gives the results of detection of treponemes when the rabbits' lymph nodes were examined before treatment, and the results of the transfer of nodes to other rabbits.

Table III shows that, in the lymph nodes before treatment, treponemes were found in examinations by the silver impregnation method in 36 cases and by darkfield microscopy and the fluorescent antibody method in five and six cases respectively. while by the two latter methods 'treponeme-like structures' were found in eight and thirteen cases.

After the transfer of lymph nodes to 75 healthy rabbits, darkfield positive chancres developed in 32 cases, and in fourteen others the results of serological tests became positive with absence of clinical manifestations. In 29 there were no clinical or serological manifestations. This small percentage of positive results of transfer of rabbits' lymph nodes before treatment shows that this method is not 100 per cent. conclusive for determining the existence of infection, and cannot be taken as a reliable indicator of the presence of treponemes. This may perhaps be due to there being only a small number of treponemes in the lymph nodes and to the treponemes having had to adapt to the tissues of the new host.

It should be noted that the rabbits' lymph nodes were very small. Each node was used not only for infecting healthy rabbits, but also for microscopic examination by a number of methods. Consequently the amount of material used for each method of examination was minute. Despite this, infection of the rabbits was nonetheless achieved in a fairly substantial percentage of cases, which would undoubtedly have been greater if a larger quantity of material had been used for infecting.

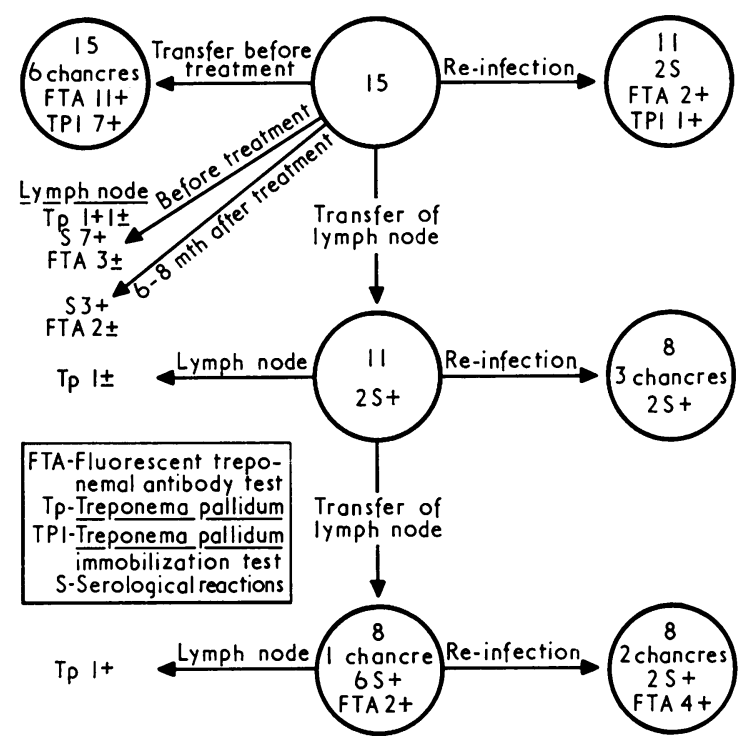

FIG. 1 Results of treatment with bicillin I 42,000 units per kg. 2 to 3 years after infection

After the treatment of fifteen rabbits with 42,000 units of bicillin I per kg. 2 to 3 years after infection (Fig. 1), a first passage was made from eleven rabbits, the remainder having died by the time of transfer. In two of the first-passage rabbits standard serological test results became positive, and treponemes were found in one in preparations from lymph nodes impregnated with silver by Morozov's method. In a second passage, among eight rabbits to which lymph nodes had been transferred from first-passage rabbits, a darkfield positive chancre developed in one, positive standard, FTA, and TPI tests in one, and a weakly positive fluorescent antibody test in one. In the five remaining rabbits weakly positive results were obtained in the standard tests. Treponemes in the rabbit's lymph nodes were found in preparations impregnated by Morozov's method in only one second-passage rabbit. In this and the rabbit in the first-passage, examination by the fluorescent antibody method also revealed treponeme-like structures in the lymph nodes, and examination by dark-

TABLE III Lymph nodes of 74 rabbits 2 to $2 \frac{1}{2}$ years after infection

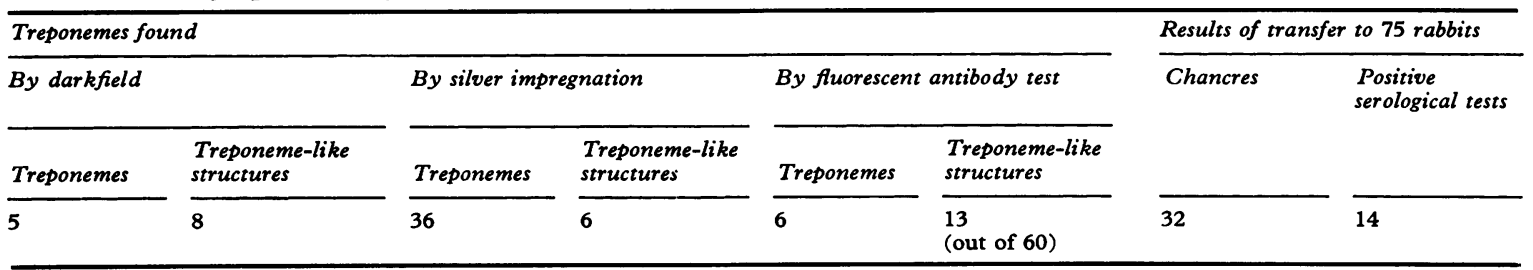


field microscopy showed treponeme-like structures in the same first-passage rabbit.

After re-infection of treated rabbits with the same strain 6 months after the end of treatment, no chancres formed. Before re-infection, all the serological tests were negative. In two out of the eleven, positive results were obtained in standard serological tests, in two the results of the fluorescent antibody test were positive, and in one the TPI test was positive while the standard test results were negative. Re-infection of first-passage rabbits produced chancres in three and positive standard test results in two. After re-infection of second-passage rabbits, chancres were found in two and the serological tests results became positive in two (fluorescent antibody test positive in four).

Equally unsatisfactory results were obtained when rodents were treated with 84,000 units of bicillin I per $\mathrm{kg}$. The long-term results of treatment of syphilis with bicillin I in relation to the time when treatment began are given in Table I. Out of thirteen first-passage rabbits, a chancre formed in two and serological test reactions became weakly positive in five. In the lymph nodes of first-passage rabbits treponemes were found in one case by darkfield microscopy and in two in preparations impregnated by Morozov's method, while in two first-passage rabbits treponeme-like structures were found. Among the second-passage rabbits, treponemes were found in the lymph nodes in one rabbit by the fluorescent antibody method.

Unsatisfactory results were also obtained after re-infection. Chancres did not form in any of twelve treated rabbits and the serological test results became positive in four; one rabbit died. After re-infection of first- and second-passage rabbits, two chancres formed in each series. The absence of infection after re-infection of the treated and most of the passage rabbits shows that the rabbits had not been cured.

Considerably better results were obtained when twenty rabbits were treated with 168,000 units per kg. (Table II). Of sixteen first-passage and eleven second-passage rabbits none formed chancres, but treponemes were found in three first- and secondpassage rabbits in lymph node preparations impregnated by Morozov's method, while treponemelike structures were found in one rabbit of each passage by the fluorescent antibody method. When seventeen treated rabbits were re-infected, a chancre formed in one, standard serological test results became weakly positive in three, and the fluorescent antibody test became positive in eight. When firstpassage rabbits were re-infected, chancres formed in five out of twelve and serological reactions became positive in eight; when second-passage rabbits were re-infected, chancres formed in four out of ten and serological reactions became positive in three. The result is better than for an 84,000 units dose, but the presence of treponemes in lymph nodes and the relatively small percentage of infections of the rabbits after re-inoculation show that a substantial number of rabbits were not cured.

21 rabbits were treated with a total dose of 200,000 units of bicillin I per kg. given in four injections of $50,000 \mathrm{u}$. at 5 -day intervals. No chancre formed in either the first or second passage. In the first passage, serological test results were weakly positive on one occasion in one out of fourteen rabbits, while in the second passage there were neither clinical nor serological manifestations. Treponemes were found by the silver impregnation method in two cases and treponeme-like structures in two cases, in the first passage. In the second passage no treponemes were found. In re-infected treated rabbits, chancres formed in two out of eight, and serological test results became positive in six. In re-infected firstpassage rabbits, chancres formed in four out of ten, and serological reactions became positive in two; after re-infection in the second-passage rabbits, chancres developed in two out of nine and serological reactions became positive in two.

Thus, although a large enough overall dose of bicillin I was administered, in some cases treponemes were discovered in passage rabbits' lymph nodes, and re-infection produced only a small percentage of infections.

Fig. 2 (overleaf) shows the different percentages of re-infection in treated and passage rabbits related to the duration of the disease and when treatment began. Absence of manifestations in healthy rabbits after transfer of lymph nodes from treated and from passage rabbits, merely shows that the treponemes present were of low virulence and few in number. It is unlikely that the treponemes found were not Treponema pallidum but Treponema cuniculi, since the rabbits had displayed no clinical or serological manifestations before the experiment.

Comparison of the results of treating with the same doses of bicillin I rabbits with chancres and rabbits 2 to 3 years after infection shows that the results are worse in the latter group. This supports the view of Collart and his colleagues that, even after penicillin treatment in the late stages of syphilis, some rabbits remain which, though cured in a clinical sense, are not cured in a biological sense.

These experiments also explain the positive TPI and fluorescent antibody test results obtained in human subjects who have been 'adequately' treated. They can be explained by the presence of treponemes with reduced pathogenicity but evidently adequate 


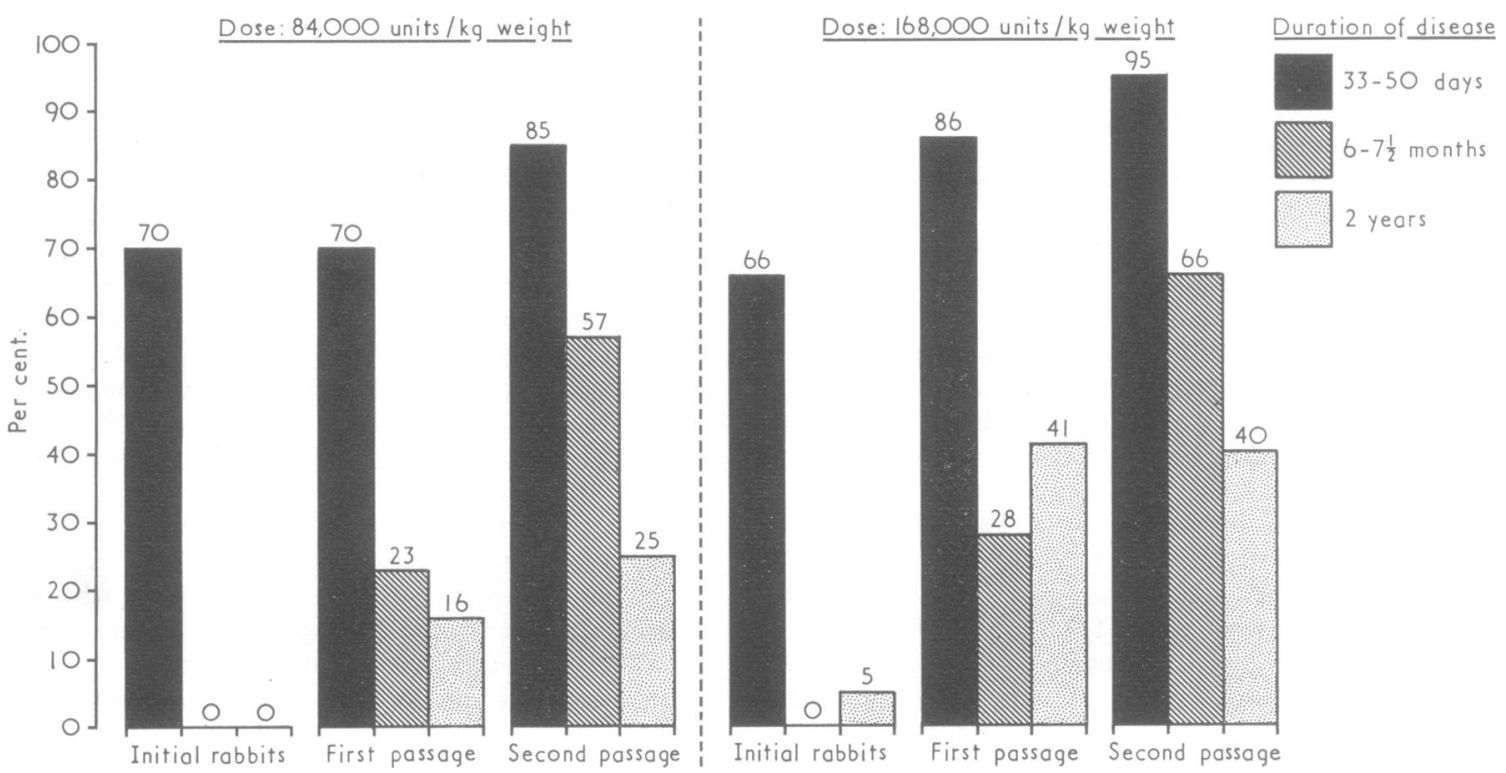

FIG. 2 Percentage of re-infection of treated and passage rabbits related to duration of disease when treated

antigenicity, since results in the two tests remain positive. It should be pointed out, of course, that even negative results of serological tests in rabbits do not invariably indicate that syphilis is absent.

Although treponemes may persist after treatment in human subjects, they do not seem to represent any risk of infection for their consorts. However, given conditions unfavourable to the host organism and favourable to the treponemes, late forms of syphilis might occur in the patient himself.

The experiments show that it is necessary both to improve our methods of treating late forms of syphilis and to devise more exact criteria of cure of syphilis.

\section{Summary and conclusions}

(1) A dose of 42,000 units per $\mathrm{kg}$. of bicillin I (benzathine penicillin) is not sufficiently effective for the treatment of rabbits with either recently contracted or late syphilis.

(2) A dose of 84,000 units per $\mathrm{kg}$. of bicillin I is sufficiently effective if treatment is started early (though failures may occur in individual rabbitsa chancre formed in one out of 34 first-passage rabbits in our experiments), but fails to cure a substantial number of the rabbits if treatment is started 2 to 3 years after infection.

(3) When 168,000 and 200,000 units of bicillin I per kg. were administered to rabbits 2 to 3 years after infection, there were no clinical manifestations in the first- and second-passage rabbits, but in some of these treponemes were found in the lymph nodes, and re-infection of treated and passage rabbits produced a relatively small percentage of infections, which indicates that in several rabbits the syphilis had not been cured.

(4) The experiments show that it is possible to explain positive TPI and fluorescent antibody test results by the presence of treponemes in treated rabbits, and that it is necessary to try to find better methods of treatment and to establish stricter criteria of cure of syphilis in humans.

\section{References}

Collart, P., Borel, L. J., and Durel, P. (1962a) Ann. Inst. Pasteur., 102, 596

$\longrightarrow,-,-\longrightarrow$ (1962b) Ibid., 103, 953

-, DUNOYER, M., and DUNOYER, F. (1967) WHO/VDT/ RES 67/126

- and Durel, P. (1964) Ann. Derm. Syph., 91, 485

Fribourg-Blanc, A., Niel, G., and Mollaret, $H$. (1966) Bull. Soc. Path. exot., 59, 54

Goldman, J. N., and GIRARD, K. F. (1967) Arch. Ophthal. (Chicago), 78, 47

GuTHE, T., and IDSøE, O. (1967) WHO/VDT/67/341

OvČrnNIKov, N. M. (1955a) 'Eksperimentalni sifilis'. Medgiz, Moscow

- (1955b) Vestn. Vener. Derm, No. 6, p. 51

-, Kucinska, E. P., and Zelikova, R. L. (1953) 'Voprosi dermatologii'. Medgiz, Moscow

- and KORBUT, S. E. (1959) 5 vsesousnii s'esda dermatovenereologov, 14-19. Dekabr, Leningrad 

USSR

(1960) Trudi 2 s'esda dermatovenerologov

(1965) Bull. Wld Hlth Org., 32, 861

, Kutukova, K. S., and Korbut, S. E. (1957)

Vestn. Derm. Vener., 31, No. 1, p. 27

Smith, J. Lawton, and Israel, C. W. (1967) Arch. Ophthal (Chicago), 77, 474

WILLCOX, R. R. (1964) Ibid., 40, 90

Yobs, A., Rockwell, D., and ClaRK, J. (1964) Ibid., 40, 248

Résultats à long terme du traitement pénicillinique dans la syphilis récente et tardive du lapin

SOMMAIRE

(1) Une dose de $42.000 \mathrm{u} / \mathrm{kg}$ de Bicilline I (benzathinepénicilline) n'est pas suffisamment active dans le traitement de lapins présentant aussi bien une syphilis récemment contractée qu'une syphilis tardive.

(2) Une dose de $84.000 \mathrm{u} / \mathrm{kg}$ de Bicilline I a une activité suffisante si le traitement est commencé tôt (quoiqu'il puisse y avoir des échecs chez certains lapins: au cours de nos expériences, un chancre s'est développé chez un des 34 lapins de premier passage) mais cette dose ne réussit pas à guérir un nombre suffisant de lapins si le traitement est commencé 2 à 3 ans après l'infection.

(3) Quand on administra 168.000 et $200.000 \mathrm{u} / \mathrm{kg}$ de Bicilline I à des lapins 2 à 3 ans après l'inoculation, il n'y eut pas de manifestation clinique chez les lapins au premier et au second passage mais, chez quelques-uns, des tréponèmes furent trouvés dans les ganglions et la réinoculation des lapins traités et des lapins ayant servi aux passages donna un relativement bas pourcentage d'infection, ce qui indique que chez plusieurs lapins la syphilis n'avait pas été guérie.

(4) Ces expériences montrent qu'il est possible d'expliquer la positivité du TPI et du FTA par la présence de tréponèmes chez des lapins traités, qu'il est nécessaire d'essayer de trouver de meilleures méthodes de traitement et d'établir des critères de guérison de la syphilis plus stricts chez l'humain. 